\title{
Call for papers: NJL Special Issue on Corpus Linguistics and the Nordic Languages
}

The second issue of volume 37 (October 2014) of the Nordic Journal of Linguistics will be a special issue devoted to Corpus Linguistics and the Nordic Languages, edited by Gisle Andersen and Daniel Hardt. The special issue is intended to solicit contributions in which corpus data play an important role.

In the past decades a number of language corpora have been developed for the empirical study of the Nordic languages. At the same time, the methods and technology applied in corpus linguistics have developed rapidly, enabling the use of increasingly refined methods for the compilation and annotation of corpora and sophisticated analytical tools for the study of language use based on corpora. Statistical methods such as cluster analysis and regression analysis may be used to describe more reliably the correlation between the variables of time and frequency with other sociolinguistic variables. Association measures are used to account for word co-occurrence (collocation and collostruction), and measures for keyness and n-gram frequency to describe variation in and between corpora. As regards corpus metadata, more sophisticated annotation schemes that include deep-level syntactic structure are being developed, and advanced dialect corpora enable the study of variation between speakers and speaker groups with links between transcribed speech and audio/video files and geodata. Moreover, the corpus linguistic landscape has been extended to include not only hand-crafted and manually edited corpora, but also large web-based corpora that are especially fit for the study of lexical and other innovation.

There is thus a growing trend in linguistic research of using examples and/or distributional facts from corpora, and this special issue is intended to contribute to this trend. We welcome research articles that take a corpus-linguistic approach to the study of language, investigating historical or contemporary aspects of any of the languages in the Nordic region (the five Scandinavian languages, Finnish, Saami and Greenlandic). The research may take a monolingual or comparative approach to phenomena at any level of linguistic analysis, based on spoken, written or computermediated language. Authors may address empirical methodologies, novel data, or theoretical matters in any framework, regarding inter- or intra-individual variation, or changes in progress, in or among any of the Nordic language varieties. Manuscripts 
in standard formats (e.g., .doc or .pdf) should be submitted by 15 January 2014 to one of the guest editors:

$\begin{array}{ll}\text { Gisle Andersen } & \text { Daniel Hardt } \\ \begin{array}{l}\text { Department of Professional } \\ \text { and Intercultural Communication }\end{array} & \text { Department of IT Management } \\ \text { NHH Norwegian School of Economics } & \text { Copenhagen Business School } \\ \text { Helleveien 30 } & \text { DK-2920 Frederiksberg } \\ \text { NO-5045 Bergen } & \text { Denmark } \\ \text { Norway } & \text { dh.itm@cbs.dk } \\ \text { gisle.andersen@nhh.no } & \end{array}$

